\title{
THE LUNAR AND SOLAR AIR TIDES AT SIX STATIONS IN NORTH AND CENTRAL AMERICA
}

\author{
B. HAURWITZ AND ANN D. COWLEY
}

National Center for Atmospheric Research, Boulder, Colo.

\begin{abstract}
The lunar semidiurnal tide and the solar 24-, 12-, 8-, and 6-hour oscillations have been determined for the six stations Balboa, Panama; San Juan, P.R.; Aguadilla, P.R.; Burbank, Calif.; Oklahoma City, Okla.; and Greensboro, N.C.
\end{abstract}

\section{INTRODUCTION}

The lunar atmospheric tide is of great theoretical interest because it shows the response of the atmosphere to a completely known external force, namely the tidal attraction of the moon. This interest has been further increased in recent years since it appears that a lunar period may be present not only in such meteorological parameters as pressure, wind, and temperature, but also in precipitation (for instance, [4]), and sunshine duration [10].

The best documented manifestation of the lunar air tide is the semidiurnal (lunar) surface pressure oscillation. Largely through the efforts of $\mathrm{S}$. Chapman and numerous collaborators (for instance, [6]) this period is now known for more than 70 stations. These stations show that the distribution of the lunar tide is not entirely regular over the earth despite the regularity of the moon's tidal force. For about 60 of these stations the variation of the lunar tide with the seasons, which is in the same sense in both hemispheres, has also been determined: In general, the amplitude maximum occurs during the northern summer, and the daily high tides are reached latest during the northern winter.

In order to increase our knowledge of the global distribution of the lunar tide, a study has been started to analyze further data, and the present paper reports in part the results of this analysis for the first six stations. These stations with the relevant information are shown in table 1. Only the pressure oscillations will be discussed here.
Results of analyses of wind and temperature (not successful in the case of the lunar tide) will be reported later.

The observational data used for the tidal determinations were made available by the National Weather Records Center in Asheville, N.C. Bi-hourly values of the pressure were used, with the first hour being 0 (midnight) Local Standard Time. The whole material was subdivided into the three "seasons" commonly used in airtidal studies, namely

D: November, December, January, February

J: May, June, July, August

E: March, April, September, October (Equinoctial months)

In each of these seasons the days were further grouped according to the daily lunar phase integer $L$ (in its modified form which moves from 0 to 11 twice during the synodic month). For the years 1961 and 1962 these integers were computed by means of tables given by Bartels and Fanselau [3]. For the earlier years punched cards based on a compilation by Bartels [2] were made available by Dr. J. C. Cain of the Goddard Space Flight Center at NASA.

For the stations Balboa, Oklahoma City, Greensboro, and Burbank the required bi-hourly mean values of the surface pressures for the different groups were computed by the National Weather Records Center. The harmonic analysis of these values was performed on an IBM 1620 computer at the High Altitude Observatory of NCAR.

TABLE 1.-List of stations

\begin{tabular}{|c|c|c|c|c|c|}
\hline Station & $\begin{array}{l}\text { Lat. } \\
\left({ }^{\circ} \mathrm{N} .\right)\end{array}$ & $\begin{array}{l}\text { Long. } \\
\left({ }^{\circ} \mathrm{W} .\right)\end{array}$ & $\begin{array}{l}\text { Alt. } \\
\text { (ft.) }\end{array}$ & Years of Record & $\underset{\text { Days }}{\text { Number of }}$ \\
\hline $\begin{array}{l}\text { Balboa, Panama } \\
\text { San Juan, P.R. } \\
\text { Aguadilla, P.R. (Ramey A F B) } \\
\text { Burbank, Calif }\end{array}$ & $\begin{array}{r}9.0 \\
18.5 \\
18.5 \\
34.2\end{array}$ & $\begin{array}{r}79.5 \\
66.1 \\
67.1 \\
118.4\end{array}$ & $\begin{array}{r}20 \\
60-80 \\
220 \\
725\end{array}$ & 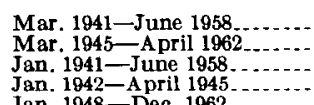 & $\begin{array}{l}6156 \\
6142 \\
6217 \\
6589\end{array}$ \\
\hline $\begin{array}{l}\text { Oklahoma City, Okla } \\
\text { Greensboro, N.C }\end{array}$ & $\begin{array}{l}35.4 \\
36.1\end{array}$ & $\begin{array}{l}97.6 \\
80.0\end{array}$ & $\begin{array}{r}886 \\
1304\end{array}$ & $\begin{array}{l}\text { Jan. 1945-Dec. 1962 } \\
\text { Nov. } 1945-D e c .1962 \ldots \\
\end{array}$ & $\begin{array}{l}6534 \\
6184\end{array}$ \\
\hline
\end{tabular}


The computing routine included the correction for linear change from midnight to midnight. This harmonic analysis gives the periods of $24,12,8$, and 6 solar hours. The determination of the lunar semidiurnal oscillation was then performed following the method developed by Chapman and Miller[5] and also described by Tschu[13]. For the two Puerto Rican stations San Juan and Aguadilla, the original data were obtained from the NWRC on magnetic tape, and all calculations for these stations, including the computations of the bi-hourly mean values and the correction for linear change, were performed at NCAR on a CDC 3600 computer, because this permitted greater flexibility in experimenting with the data, especially as far as the omission of days with greater variability of the pressure was concerned.

At all six stations one or more changes in the observing routine occurred: At Aguadilla, for instance, the observations were made $30 \mathrm{~min}$. past the hour from 1941 through 1952, on the hour from 1954 on. In all these cases, the data have been divided into time intervals of uniform observations practice. The various tidal determinations have been made separately for these time intervals. Then, after the appropriate corrections of the phase constants were made, the results for the two time intervals were combined.

After the determination of the tides for the six stations was completed, some errors in the card deck for the lunar integers $L$ were discovered. During August 1942 all the lunar numbers were too small by 3 , and in the period from 1943 to 1960,18 days were assigned the wrong lunar number, but only in five instances was the difference between the correct and incorrect number greater than 1 .

For San Juan and Aguadilla the analysis was repeated with the corrected lunar deck. Table 2 shows for Aguadilla the effect of, or rather the absence of an appreciable effect, of the errors in the lunar deck. The lunar tidal oscillation is given in the customary form.

$$
L_{2}\left(p_{0}\right)=l_{2} \sin \left(30 t+\lambda_{2}\right)
$$

where $t$ is local mean lunar time, $l_{2}$ the amplitude expressed in microbars ( $\left.1 \mu \mathrm{b} .=10^{-3} \mathrm{mb} .=1 \mathrm{gm} . \mathrm{cm}^{-1} \mathrm{sec}^{-2}\right)$, $\lambda_{2}$ the phase constant in degrees. The radius of the probable error circle is denoted by $r$. The results are given separately for the time intervals I (1941-1953) and II (1954-June 1958) into which the data are separated for the computation in order to allow for the change in observing time mentioned previously. Only the harmonic constants for the three seasons, but not those for the annual means are given, because any differences due to a faulty lunar deck should show up most in the results based on less material. The first line in the table for each period gives the results obtained before elimination of the errors in the lunar deck, the second line the results with the correct deck. The data, and those for San Juan, have been analyzed under the further restriction that those days were eliminated on which the pressure during any 2-hour interval changed by more than $4 \mathrm{mb}$. As would be expected for tropical stations, very few days were eliminated because of this restriction. The results with this restriction are shown in the third line for each of the two time intervals. A comparison of the appropriate results shows that the deck errors, as well as the 4-mb. restriction, gave results which are not different from those obtained with the corrected deck. It seemed, therefore, not necessary to recompute the lunar tide for the other stations with the corrected deck or to introduce the 4-mb. restriction for the other stations. However, the results for Aguadilla and San Juan given in table 3 are computed with the corrected lunar deck.

A somewhat surprising feature is the large value of $l_{2}$ during the $D$ season for the time interval II at Aguadilla. If $d$ is the distance between two points representing two oscillations in a polar diagram, $e^{2}$ the sum of the squares of the probable errors of the twa determinations, then $2^{-d^{2} / e^{2}}$ is the probability that such a separation between the oscillations is due to pure chance, as shown by Bartels [1]. In the present case, this probability is $1: 4$ so that one might well expect to find such a difference accidentally. Actually, because of the limited number of data available for the determination, the probability is even higher than indicated by the test which assumes a very large number of data. It will also be noted that the probable-error circle during the second time interval is larger than one would expect from its value during the first time interval and allowing for the difference in the length of the time intervals.

TABLE 2.-Comparison of lunar tidal computation for Aguadilla

\begin{tabular}{|c|c|c|c|c|c|c|c|c|c|c|}
\hline & \multicolumn{3}{|c|}{$D$ Season } & \multicolumn{3}{|c|}{$J$ Season } & \multicolumn{3}{|c|}{$E$ Season } & \multirow[b]{2}{*}{ Length of Record } \\
\hline & $\begin{array}{c}l_{2} \\
(\mu \mathrm{b} .)\end{array}$ & $\begin{array}{c}\lambda_{2} \\
\text { (deg.) }\end{array}$ & $\stackrel{r}{(\mu b .)}$ & $\underset{(\mu \mathrm{b} .)}{l_{2}}$ & $\begin{array}{c}\lambda_{2} \\
\text { (deg.) }\end{array}$ & $(\mu \mathrm{b})$. & $\begin{array}{c}l_{3} \\
(\mu \mathrm{b} .)\end{array}$ & $\begin{array}{c}\lambda_{2} \\
\text { (deg.) }\end{array}$ & $\begin{array}{c}r \\
(\mu \mathrm{b} .)\end{array}$ & \\
\hline $\begin{array}{l}\text { Period I } \\
\text { Deck error } \\
\text { No error } \\
\text { 4-mb. restriction. }\end{array}$ & $\begin{array}{l}\text { 43. } 6 \\
\text { 43. } \\
43.2\end{array}$ & $\begin{array}{l}49 \\
49 \\
49.9\end{array}$ & $\begin{array}{l}4.4 \\
4.4 \\
4.0\end{array}$ & $\begin{array}{l}54.9 \\
56.7 \\
57.0\end{array}$ & $\begin{array}{l}74 \\
75 \\
76.4\end{array}$ & $\begin{array}{l}5.8 \\
5.5 \\
5.6\end{array}$ & $\begin{array}{l}51.0 \\
51.0 \\
49.7\end{array}$ & \begin{tabular}{l|}
77 \\
77 \\
76.8
\end{tabular} & $\begin{array}{l}6.1 \\
6.1 \\
6.5\end{array}$ & $\begin{array}{l}1941-53 \\
13 \mathrm{yr} .\end{array}$ \\
\hline $\begin{array}{l}\text { Deck error ........ Period II } \\
\text { No error } \\
\text { 4-mb. restriction }\end{array}$ & $\begin{array}{l}60.4 \\
60.6 \\
60.6\end{array}$ & $\begin{array}{l}44 \\
44 \\
44.3\end{array}$ & $\begin{array}{l}12.4 \\
12.2 \\
12.2\end{array}$ & $\begin{array}{l}48.9 \\
48.6 \\
48.6\end{array}$ & $\begin{array}{l}76 \\
74 \\
74.4\end{array}$ & $\begin{array}{l}9.5 \\
9.8 \\
9.8\end{array}$ & $\begin{array}{l}35.3 \\
36.7 \\
37.0\end{array}$ & \begin{tabular}{l|}
71 \\
73 \\
78.4
\end{tabular} & $\begin{array}{l}7.9 \\
7.7 \\
6.9\end{array}$ & $\begin{array}{l}1954-J u n e ~ ' 58 \\
4.5 \mathrm{yr} .\end{array}$ \\
\hline
\end{tabular}


TABLE 3.-Lunar semidiurnal pressure oscillation

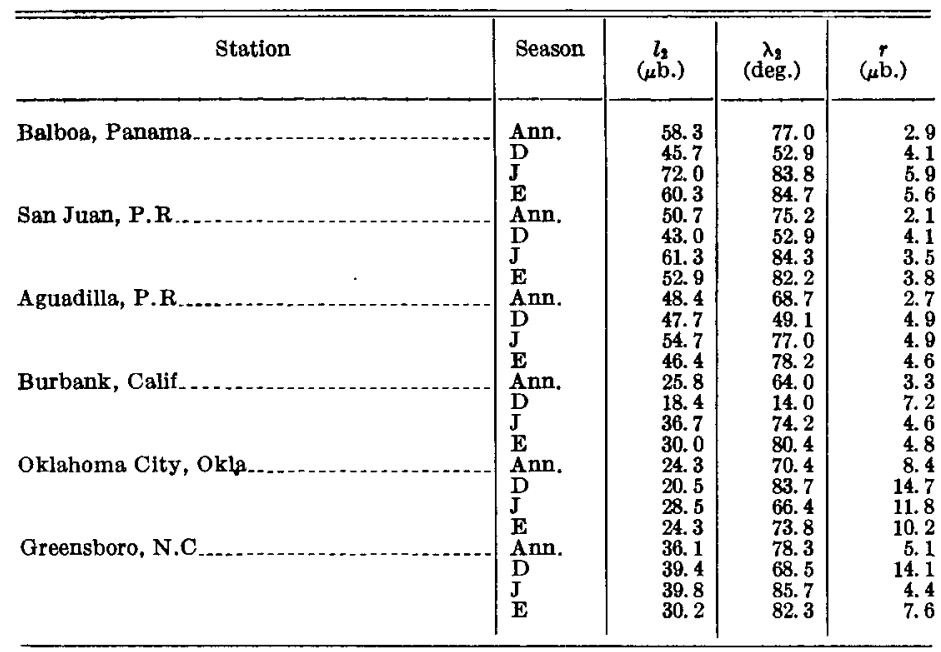

\section{THE LUNAR SEMIDIURNAL TIDE}

The results of the lunar tidal determinations are shown in table 3 which gives the amplitude $l_{2}$, the phase angle $\lambda_{2}$, and the radius of the probable error circle $r$. In general, the annual mean amplitude shows the well-known decrease with distance from the equator. The amplitude is higher at Greensboro, N.C. than at Oklahoma City and at Burbank, Calif., which indicates the westward decrease of the amplitude over the United States found previously by Chapman and Westfold [6].

The seasonal variation of the lunar semidiurnal tide is generally characterized by a smaller phase constant (later high tide) during the $D$ months than in the other two seasons. This is also shown by the data presented in table 3 , with the exception of Oklahoma City. But here the radii of the probable error circles are so large that little if any weight can be given to this anomaly. The angle between the line from the origin to the point in the harmonic dial representing the oscillation and the tangent to the error circle is $\sin ^{-1}\left(r / l_{2}\right)$ so that the phase constant for the $D$ months at Oklahoma City may be given as $84^{\circ} \pm 46^{\circ}$, showing clearly that the lunar tide is not well determined.

Another feature of the seasonal variation of the lunar tide is the maximum amplitude during the $J$ months which is shown at all stations given in table 3 , although at some stations with large probable errors, the difference between the $D$ and $J$ months is statistically not significant.

In considering the data in table 3 , it should be remembered that the determination of an oscillation cannot be considered satisfactory if the amplitude is not at least three times larger than the radius of the probable error circle. The probable error circle is commonly used in considering the reliability of the determinations of geophysical periodicities, largely thanks to the pioneering efforts of Bartels. It could, of course, be replaced by some other statistical measure. However, the use of the
TABLE 4.-Probability of large amplitudes in random data

\begin{tabular}{|c|c|c|}
\hline$A / r$ & $m=12$ & $m=\infty$ \\
\hline $\begin{array}{l}0.5 \\
1.5 \\
1.5 \\
2.5 \\
2.5 \\
3.5 \\
4.5 \\
4.5 \\
5.5 \\
6- \\
7 \\
8 \\
9\end{array}$ & $\begin{array}{cc}1: & 1.2 \\
1: & 1.9 \\
1: & 3.9 \\
1: & 9.4 \\
1: & 23.8 \\
1: & 61 \\
1: & 146 \\
1: & 324 \\
1: & 652 \\
1: & 1200 \\
1: & 3290 \\
1: & 8100 \\
1: 1200 \\
1: 19700 \\
1: 26900\end{array}$ & $\begin{array}{rr}1: & 1.2 \\
1: & 2.0 \\
1: & 4.7 \\
1: & 15.8 \\
1: & 7.4 \\
1: & 493 \\
1: & 4870 \\
1: 59900 \\
1: 1.11 \cdot 10^{2} \\
1: 29.4 \cdot 10^{\circ}\end{array}$ \\
\hline
\end{tabular}

probable error makes the comparison with earlier results much easier and permits also the direct application of various theorems derived for it to the interpretation of the results.

If the amplitude $A$, the radius of the probable error circle $r$, and the number of groups of data from which the probable error circle was computed are known, the probability $p$ can be estimated that an amplitude of this magnitude may be found in random data (Haurwitz [7]). This probability $p$ is shown in table 4 for $m=12$, and for $m=\infty$. The number 12 was selected because the Chapman-Miller method used here is in effect based on the determination of the lunar tide $L_{2}$ by means of the solar semidiurnal oscillation $S_{2}$ grouped into 12 lunar phase groups. If $A=3 r$, the probability that such an amplitude is found in random data is $1: 60$, but this probability decreases rapidly as $A$ increases relative to $r$. Table 4 should help in the understanding of the significance of the probable-error circle in connection with the presentation of geophysical oscillations.

While the amplitudes of the lunar tide at San Juan and Aguadilla agree reasonably well, the phase angles differ by about $7^{\circ}$ despite the close proximity of the stations. Similar phase angle differences will be found for the solarday oscillations at both stations (table 5). Since allowance has been made for the fact that the observations were not all made on the hour, the explanation cannot be sought in a change of the observing routine, and in fact no explanation is readily apparent. Correspondence with the National Weather Records Center on this point indicated that some minor changes may have been made in the times when the observations were taken, but it is not possible to reconstruct such hypothetical changes now.

It is of some interest to mention here briefly some results of a pilot study undertaken prior to the determination of lunar tides on a large scale. In order to have a statistical estimate of how many data might be required for a reliable determination of the lunar tide an analysis was performed using the pressure observations at Balboa for the year 1953. The lunar tidal pressure oscillation was found to be:

$$
44.8 \mu \text { b. } \sin \left(30 t+84.8^{\circ}\right) \text {, }
$$


TABLE 5.-Solar-day oscillations

\begin{tabular}{|c|c|c|c|c|c|c|c|c|c|c|c|c|c|}
\hline Station & Season & $s_{1}(\mu \mathrm{bb})$. & $\sigma_{1}$ (deg.) & $r_{1}(\mu \mathrm{b})$. & $s_{2}(\mu \mathrm{b})$. & $\sigma_{2}$ (deg.) & $r_{2}$ & $s_{3}(\mu \mathrm{b})$. & $\sigma_{3}(\mathrm{deg})$. & $\tau_{3}(\mu \mathrm{b})$. & $84(\mu \mathrm{b})$. & $\sigma_{4}$ (deg.) & $r_{4}(\mu \mathrm{b})$. \\
\hline Balboa. & \multirow{12}{*}{\begin{tabular}{|l} 
Ann. \\
D \\
J \\
E \\
Ann. \\
D \\
$\mathbf{J}$ \\
E \\
Ann. \\
D \\
$\mathbf{J}$ \\
$\mathbf{E}$ \\
Ann. \\
D \\
J \\
E \\
Ann. \\
D \\
J \\
A \\
Ann. \\
D \\
J \\
E
\end{tabular}} & \multirow{12}{*}{ 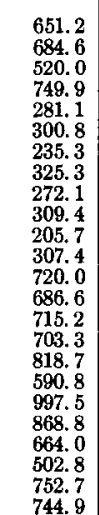 } & \multirow{12}{*}{$\begin{array}{r}7.5 \\
8.2 \\
9.4 \\
95.4 \\
535.4 \\
341.8 \\
11.4 \\
351.2 \\
336.4 \\
334.0 \\
3348.0 \\
331.1 \\
358.2 \\
350.8 \\
350.8 \\
339.8 \\
339.7 \\
336.6 \\
345.2 \\
345.3 \\
355.3 \\
339.9 \\
347.7\end{array}$} & & \multirow{12}{*}{ 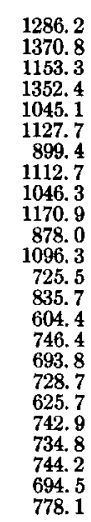 } & \multirow{12}{*}{$\begin{array}{l}153.4 \\
157.3 \\
148.2 \\
1144.2 \\
149.7 \\
152.4 \\
146.0 \\
149.9 \\
146.9 \\
149.7 \\
142.0 \\
146.8 \\
150.0 \\
155.8 \\
142.1 \\
150.2 \\
148.4 \\
156.0 \\
138.2 \\
149.2 \\
1188.5 \\
165.2 \\
150.0 \\
158.7\end{array}$} & & \multirow{12}{*}{$\begin{array}{r}47.7 \\
80.4 \\
36.5 \\
47.4 \\
47.5 \\
170.5 \\
99.6 \\
54.1 \\
77.5 \\
190.3 \\
74.8 \\
81.8 \\
88.9 \\
27.7 \\
99.7 \\
69.9 \\
55.3 \\
244.4 \\
130.9 \\
107.2 \\
78.6 \\
256.0 \\
78.1 \\
48.7\end{array}$} & \multirow{12}{*}{$\begin{array}{r}49.8 \\
29.5 \\
10.3 \\
55.3 \\
42.0 \\
18.9 \\
163.1 \\
163.1 \\
63.3 \\
32.2 \\
2.9 \\
131.1 \\
44.4 \\
16.4 \\
357.6 \\
144.1 \\
23.1 \\
33.5 \\
351.3 \\
149.4 \\
21.4 \\
34.4 \\
156.8 \\
358.6 \\
358.9\end{array}$} & & \multirow{12}{*}{$\begin{array}{r}41.4 \\
48.1 \\
20.3 \\
58.1 \\
47.6 \\
68.0 \\
36.8 \\
50.6 \\
45.1 \\
60.4 \\
34.4 \\
48.4 \\
30.6 \\
88.0 \\
19.0 \\
17.7 \\
56.6 \\
108.2 \\
46.8 \\
20.8 \\
27.3 \\
83.6 \\
23.9 \\
8.5\end{array}$} & \multirow{12}{*}{$\begin{array}{l}172.0 \\
182.1 \\
150.9 \\
170.8 \\
166.5 \\
191.8 \\
137.6 \\
154.6 \\
155.6 \\
177.3 \\
133.1 \\
144.6 \\
226.9 \\
202.0 \\
2027.1 \\
300.0 \\
193.1 \\
185.3 \\
196.8 \\
2127.3 \\
184.0 \\
207.7 \\
110.5 \\
85.3\end{array}$} & \multirow[b]{2}{*}{$\begin{array}{l}6.2 \\
3.4\end{array}$} \\
\hline & & & & $\begin{array}{l}6.8 \\
8.5 \\
80\end{array}$ & & & & & & $\begin{array}{l}3.4 \\
5.4 \\
3.9\end{array}$ & & & \\
\hline Sun Juan. & & & & - & & & & & & & & & \\
\hline & & & & $\begin{array}{l}7.8 \\
7.4\end{array}$ & & & & & & $\begin{array}{l}3.3 \\
3.3\end{array}$ & & & $\begin{array}{l}2.9 \\
2.2 \\
2.2\end{array}$ \\
\hline Aguadilla & & & & 1.4 & & & $\cdots$ & & & 2.1 & & & \\
\hline & & & & $\begin{array}{l}5.2 \\
7.3\end{array}$ & & & & & & $\begin{array}{l}2.4 \\
3.2\end{array}$ & & & $\begin{array}{l}2.4 \\
2.4\end{array}$ \\
\hline Burbank. & & & & 12.1 & & & & & & 4.2 & & & 2.7 \\
\hline Oklahoma Cit & & & & $\begin{array}{l}0.0 \\
9.6\end{array}$ & & & & & & $\begin{array}{l}3.0 \\
3.2\end{array}$ & & & 2. \\
\hline & & & & 29.9 & & & & & & 11.6 & & & 11.5 \\
\hline Freensboro. & & & & 22.2 & & & & & & 9.0 & & & 11.3 \\
\hline - & & & & 年. 6 & & & $\cdots$ & & & 12.3 & & & 111. \\
\hline & & & & $\begin{array}{l}19.0 \\
19.7\end{array}$ & & & & & & 4.4 & & & \\
\hline
\end{tabular}

with a radius of the probable error circle of $12.3 \mu \mathrm{b}$. Since the error decreases inversely proportional to the square root of the number of observations one should expect for $17.5 \mathrm{yr}$. of data a probable error of $2.95 \mu \mathrm{b}$., very close to the value given in table 3 . It is also interesting to note that a determination of the lunar tide from one day's data could be expected to have a probable error of about $230 \mu \mathrm{b}$.

\section{THE SOLAR-DAY OSCILLATIONS}

The harmonic constants for the solar-day oscillations with periods of $1 / n$ mean solar days, $n=1,2,3,4$, are given in table 5 for the annual means, and for the three seasons in the form

$$
S_{n}\left(p_{0}\right)=s_{n} \sin \left(15 n t+\sigma_{n}\right)
$$

where $s_{n}$ and $\sigma_{n}$ are amplitude and phase constant of the $n$th oscillation, $S_{n}$, and $t$ mean solar time in hours. Since the data had to be grouped according to the lunar phase integer for the computation of $L_{2}$ the solar-day oscillations were determined first for these 12 groups. Table 5 gives the mean values of the harmonic constants for these 12 groups and the radii of the probable error circles for these means as computed from the grouping. In the case of the solar semidiurnal oscillation the errors computed in this manner would be too large because they would contain the effect of the lunar tide. The errors given in table 3 for the lunar tide are actually the residual errors applying both to the solar and lunar semidiurnal oscillations. They are not repeated in table 5. No errors are given for the annual means of the solar oscillations in table 5. They are comparable to the errors for the seasonal values.

The solar 24-hour oscillation $S_{1}$ is known to be irregularly distributed over the earth. In table 5 the two stations on the island of Puerto Rico show a much smaller amplitude than the other stations. The pressure maximum occurs about 5:30 a.m. at Balboa, but in general between 6:00 and 8:00 a.m. at the other stations. An analysis of the global distribution of this oscillation (strictly speaking, its annual mean) had shown that the worldwide maximum, freed of local influences, occurs at 5:00 a.m. approximately [8]. The data of table 5 show a seasonal variation of $S_{1}$, but this variation is not uniform.

The solar semidiurnal oscillation $S_{2}$ shows the wellknown decrease with increasing latitude, although this decrease is not quite regular, as shown in table 5 by Greensboro in the eastern part of the United States. It had already been noted by Spar [12] that the amplitudes are large along the east coast of the United States. All stations have their minimum amplitude in summer, another well-known characteristic of the semidiurnal oscillation.

The main term of the 8-hour solar oscillation $S_{3}$ is characterized by a phase shift of $180^{\circ}$ from one solstice to the next (for instance, [11]). Since the latitude dependence of the amplitude of $S_{3}$ is mainly proportional to the associated Legendre functions $P_{4}^{3}(\varphi)$ where $\varphi$ is the latitude, it has its maximum at $30^{\circ} \mathrm{N}$. and S. Another term, about $1 / 3$ as large, and without such a pronounced annual variation, has its maximum at the equator. Accordingly, it is seen in table 5 that the most southerly stations have a smaller phase shift from summer to winter than the stations at higher latitudes. The maximum amplitude occurs during the winter months, another well established feature of this oscillation.

The 6-hour solar oscillation $S_{4}$ has lately been studied by Kertz [9] who combined all the earlier data and computed some additional ones. Its main term is characterized by the associated Legendre function $P_{5}^{4}(\varphi)$ with a maximum amplitude around $25^{\circ}$ latitude and with a pronounced seasonal variation. The harmonic parameters in table 5 show such a strong seasonal variation, and, except for Balboa, a maximum amplitude during the $D$ months, in agreement with Kertz's result for the term with $P_{5}^{4}(\varphi)$ 
The peculiar phase differences of the solar-day oscillations at San Juan and Aguadilla have already been commented on in connection with the lunar tide.

\section{ACKNOWLEDGMENTS}

Our thanks are due to the Director and staff of the National Weather Records Center who furnished the data for this work, performed many of the preliminary calculations, and patiently answered our many inquiries.

\section{REFERENCES}

1. J. Bartels, "Statistical Methods for Research on Diurnal Variations," Terrestrial Magnetism and Atmospheric Electricity, vol. 37, No. 3, 1932, pp. 291-302.

2. J. Bartels, "A Table of Daily Integers, 1902-1952, Seasonal, Solar, Lunar, and Geomagnetic," Scientific Report No. 2 on contract AF 19(604)-503, Geophysical Institute, University of Alaska, 1954, $18 \mathrm{pp}$.

3. J. Bartels and G. Fanselau, "Geophysikalischer Mond-Almanach," Zeitschrift für Geophysik, vol. 13, 1937, pp. 311-328.

4. G. W. Brier, "Diurnal and Semidiurnal Atmospheric Tides in Relation to Precipitation Variations," Monthly Weather Review, vol. 93, No. 2, Feb. 1965, pp. 93-100.

5. S. Chapman and J. C. P. Miller, "The Statistical Determination of Lunar Daily Variations in Geomagnetic and Meteorological Elements," Monthly Notices, Royal Astronomical Society, Geophysical Supplement, vol. 4, No. 9, May 1940, pp. 649-669.

6. S. Chapman and K. C. Westfold, "A Comparison of the Annual Mean Solar and Lunar Atmospheric Tides in Barometric
Pressure, As Regards Their Worldwide Distribution of Amplitude and Phase," Journal of Atmospheric and Terrestrial Physics, vol. 8, No. 1/2, Feb. 1956, pp. 1-23.

7. B. Haurwitz, "Tidal Phenomena in the Upper Atmosphere," WMO Technical Note No. 58 (WMO No. 146.TP. 69) World Meteorological Organization, 1964, 26 pp.

8. B. Haurwitz, "The Diurnal Surface-Pressure Oscillation," Archiv für Meteorologie, Geophysik und Bioklimatologie, Ser. A, 1965 (in press).

9. W. Kertz, "Partialwellen in den halb- und vierteltäglichen gezeitenartigen Schwingungen der Atmosphäre," Archiv für Meteorologie, Geophysik und Bioklimatologie, Ser A, vol. 11, No. 1, 1959, pp. 48-63.

10. I. A. Lund, "Indications of a Lunar Synodical Period in United States Observations of Sunshine," Journal of the Atmospheric Sciences, vol. 22, No. 1, Jan. 1965, pp. 24-39.

11. M. Siebert, "Atmospheric Tides," Advances in Geophysics, vol. 7, Academic Press, 1961, pp. 105-182.

12. J. Spar, "Characteristics of the Semidiurnal Pressure Wave in the United States," Bulletin of the American Meteorological Society, vol. 33, No. 10, Dec. 1952, pp. 438-441.

13. K.-K. Tschu, "On the Practical Determination of Lunar and Luni-Solar Daily Variations in Certain Geophysical Data," Australian Journal of Scientific Research, Ser. A, vol. 2, No. 1, Mar. 1949, pp. 1-24. (See also: S. Chapman, "The Calculation of the Probable Error of Determinations of Lunar Daily Harmonic Component Variations in Geophysical Data: A Correction," Australian Journal of Scientific Research, Ser. A, vol. 5, No. 1, Mar. 1952, pp. 218-222.)

[Received May 4, 1965] 